\title{
Drug Induced Pure White Cell Aplasia: A Case Report and Review of Literature
}

\author{
Aisha Jamal ${ }^{1}$, Uzma Zaidi ${ }^{1, *}$, Jawad Hasan Kazmi ${ }^{2}$, Munira Borhany ${ }^{1}$, Quratulain Rizvi ${ }^{1}$ and \\ Tahir Shamsi ${ }^{1}$ \\ ${ }^{I}$ Department of Adult Clinical Haematology, National Institute of Blood Diseases and Bone Marrow Transplantation, Karachi, \\ Pakistan. \\ ${ }^{2}$ Department of Diagnostic Haematology, National Institute of Blood Diseases and Bone Marrow Transplantation, Karachi, \\ Pakistan.
}

\begin{abstract}
Pure White Cell Aplasia (PWCA) is an extremely rare haematological entity. Various causes have been implicated in its pathogenesis. We are reporting here a case of a sixty seven years old female, referred to us with the concern of febrile neutropenia and extensive oral candidiasis. Workup for secondary causes of agranulocytosis was negative. Bone marrow findings were consistent with PWCA, and in the presence of convincing previous history of amodiaquine intake, she was diagnosed as drug (amodiaquine) induced PWCA.
\end{abstract}

Keywords: Agranulocytosis, Drug induced pure white cell aplasia, Febrile neutropenia.

doi.org/10.21089/njhs.22.0088

\section{INTRODUCTION}

Pure White Cell Aplasia (PWCA) is an extremely rare haematological entity. It is identified on the basis of morphological criterion that depicts the virtual absence of myeloid precursors with intact erythropoiesis and megakaryopoeisis in bone marrow aspirate and trephine [1]. Various causes are implicated in its pathogenesis including auto-immune phenomenon [2], viral infections, thymoma [3], drug induced [4] [5], and chronic lymphocytic leukaemia [6]. It can also be idiopathic. Drug induced agranulocytosis (DIAG) is defined as sudden development of neutropenia following a particular drug exposure in an individual with normal antecedent absolute neutrophil count. Previously postulated conventional mechanisms of DIAG elaborate the role of toxic phenomenon including neutrophil necrosis and autophagy, and Immune-mediated agranulocytosis. The newer proposed mechanisms delineate the role of reactive oxygen species that oxidize the drug molecule and produce haptens responsible for eliciting immune mediated damage in the form of antibody production and cell mediated toxicity [7]. The drugs commonly ascribed to cause agranulocytosis include clozapine, anti-thyroid drugs, sulfasalazine and ticlopidine. We are reporting here, an elaborate account of drug induced agranulocytosis amodiaquine being the culprit drug. Amodiaquine belongs to the class of anti-malarials, similar in

*Address correspondence to this author at the Department of Adult Clinical Haematology, National Institute of Blood Diseases and Bone Marrow Transplantation, Karachi, Pakistan. E-mail: uzaidi26@gmail.com properties to Chloroquine, but notorious for its life threatening complications of agranulocytosis and hepatotoxicity.

\section{CASE REPORT}

A sixty-seven year old female with no known comorbids was referred to us with the concern of febrile neutropenia for last ten days. On examination, she was febrile and had extensive oral thrush. Systemic examination was completely unremarkable. The reports she brought along showed severe agranulocytosis with WBC of $1.0 \times 10^{9} / \mathrm{L}$ and absolute neutrophil count (ANC) $0.01 \times 10^{9} / \mathrm{L}$.

On thorough evaluation of past history for any previous illnesses or prolonged drug exposure, the patient recalled an episode of febrile illness three months ago. At that time she was diagnosed to have malaria (Plasmodium vivax) and was prescribed tablet basoquin (compound: amodiaquine) $500 \mathrm{mg}$ once a week. The medical record of that time showed an absolutely normal WBC of $6.7 \times 10^{9} / \mathrm{L}$ and ANC $4.2 \times 10^{9} / \mathrm{L}$. Due to some misunderstanding on her part, the patient continued to take $500 \mathrm{mg}$ of amodiaquine per day for 8 days and then $500 \mathrm{mg}$ per week for further 12 weeks. She, then presented with high-grade fever to another doctor and, received IV antibiotics. Injection Filgrastim (GCSF) $300 \mu \mathrm{g}$ subcutaneously was also given for six days but she remained unresponsive and was referred to our institute. The $\mathrm{CBC}$ at presentation showed WBC of $0.9 \times 10^{9} / \mathrm{L}$ and $\mathrm{ANC}$ of $0.02 \times 10^{9} / \mathrm{L}$ while her haemoglobin and platelet count were normal. Her peripheral smear revealed normochromic norm- 
ocytic red cell morphology, platelet anisocytosis, few lymphocytes, no abnormal cells and severe neutropenia (Fig. 1).

Her biochemistry panel was normal. An extensive work up including ANA, rheumatoid factor, HIV and acute viral serology was carried out but it turned out to be negative. Se- rum B12 and red cell folate levels were normal. Radiological investigations excluded the possibility of thymoma. Bone marrow aspirate and trephine biopsy revealed a cellularity of 40-45\% (normal for age) with absent myeloid precursors and intact erythropoiesis and megakaryopoiesis (Fig. 2).



Fig. (1). Peripheral smear showing normal RBC morphology, platelet anisocytosis, few lymphocytes and absent neutrophils.

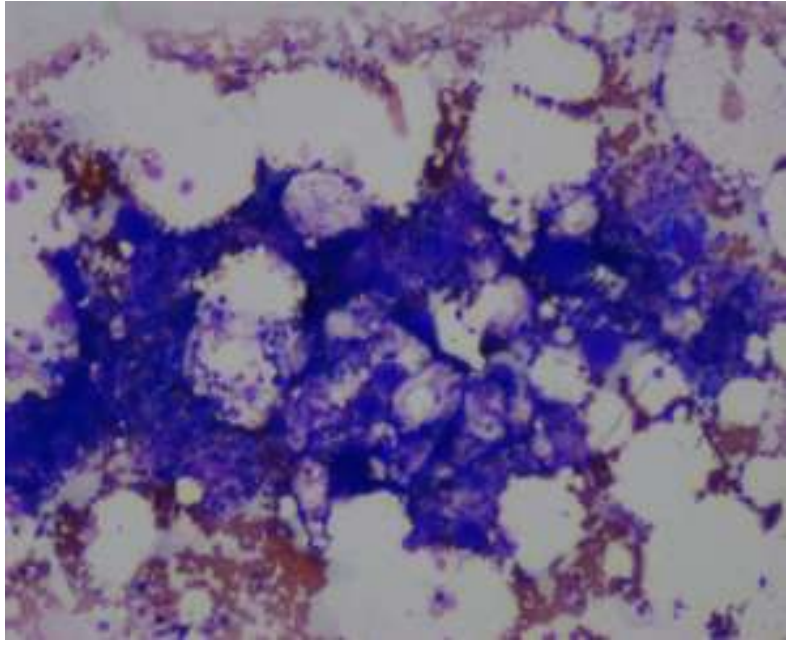

$\mathbf{A}$

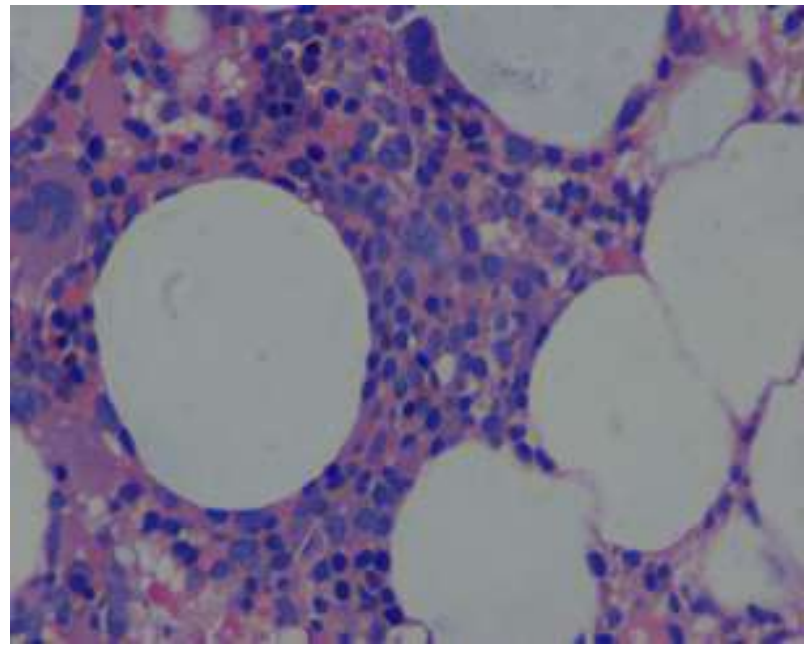

B

Fig. (2). (A) Bone marrow aspirate and (B) trephine biopsy showing cellular marrow with absent myeloid precursors.

The patient was started on broad-spectrum antibiotics after sending cultures, along with supportive care including growth factor (injection GCSF $300 \mu \mathrm{g}$ subcutaneously once a day and injection folinic acid $15 \mathrm{mg}$ thrice daily) to rescue any possible DNA damage. Her clinical status improved. She became afebrile and oral ulcers resolved, but agranulocytosis persisted over next 4 days. At this point, she was started on intravenous steroids (injection methylprednisolone $2 \mathrm{mg} / \mathrm{kg}$ per day) along with oral cyclosporine (150 mg twice daily) to overcome a possible immune cause, along with GCSF and folinic acid. The patient recovered her white cell counts completely on day thirty three of the treatment institution.

\section{DISCUSSION}

PWCA is a rare haematological disorder characterized by peripheral blood agranulocytosis with near absent myeloid precursors in bone marrow, along with normal erythropoiesis 
and megakaryopoiesis [1]. Various etiologies that are known to exist in association with PWCA exhibit the presence of cytotoxic T cells and anti-neutrophil antibodies [8]. Thymectomy and drug discontinuation are clinically useful but most of the cases require the use of immunosuppressants e.g.. steroids, intravenous immunoglobulin, cyclosporine and rituximab [9].

A number of drugs have been implicated as potential cause of agranulocytosis. The most commonly known drugs are areclonazapine, carbimazole, methimazole, ticlopidine and sulfasalazine. Less commonly involved drugs include ACE inhibitors, NSAIDS, antiarrhythmics and antimalarials [1012].

Amodiaquine is a 4-aminoquinolein derivative compound. It has anti-malarial and anti-inflammatory properties, and is similar in structure and function to Chloroquine except that it is also effective against some of the Chloroquine resistant strains. The anti-malarial effect is accredited to its ability to bind protozoal DNA and prevention of any further DNA replication, RNA formation and subsequent protein synthesis. It is readily absorbed from GI tract and immediately converted to its active metabolite desethamodiaquine which is responsible for nearly all the anti-parasitic activity. Nausea, diarrhea, skin rash and itching are some of the common side effects. Less common, yet serious side effects include agranulocytosis, and hepatotoxicity [13].

The literature search revealed two postulated mechanisms by which amodiaquine can cause agranulocytosis:the first being dose dependent inhibitory effect on myeloid precursors [14] and second, an immune phenomenon attributed to anti IgG anti-neutrophil antibodies detected in the sera of the patients that were treated with amodiaquine and later developed agranulocytosis [15]. What really led to this extreme degree of agranulocytosis in our patient remains highly speculative. We initially offered her colony stimulating agent solely and no response was demonstrated. This was followed by the combination of colony stimulators and immune modulators and after thirteen days of this coalescent treatment, her white cell counts were fully recovered.

Twenty-three cases of amodiaquine associated agranulocytosis were reported in the year 1986, seven of which were fatal. The dose prescribed for malarial prophylaxis was 400 mg per week for the minimum of three and the maximum of twenty four weeks [16]. Realizing the fact that any potential advantage that could be obtained by the use of amodiaquine as malarial prophylaxis cannot be justified due to this life threatening complication of agranulocytosis; Centers for Disease Control (CDC) took back the recommendation of its use in malarial prophylaxis in the same year. Acute malarial episodes currently are the only indication of amodiaquine administration in combination with artesunate [17].
This unfortunate event of drug induced agranulocytosis with its life threatening implications compels us to go back to our very basics. We, as physicians, must know in detail the recommended indications, dose and duration of the drug being prescribed. We should also have a sound knowledge of the possible side effects of any drug, both common and rare, and their monitoring protocols. Above all, this regrettable incident calls for the need of well-grounded doctor-patient communication and sound counseling, not only of patient but also of their care givers to avoid any such noxious incidents.

\section{CONFLICT OF INTEREST}

Declared none.

\section{ACKNOWLEDGEMENT}

Declared none.

\section{REFERENCES}

[1] Fumeaux Z, Beris P, Borisch B, Sarasin F, Roosnek E, Dayer J, et al. Complete remission of pure white cell aplasia associated with thymoma, autoimmune thyroiditis and type 1 diabetes. Eur. J. Haematol., 2003; 70(3): 186-9.

DOI:10.1034/j.1600-0609.2003.00023.x

[2] Firkin F, Prewett E, Nicholls K, Moran J. Antithymocyte globulin therapy for pure white cell aplasia. Am. J. Hematol., 1987; 25(1):101-105. DOI:10.1002/ajh.2830250111

[3] Mathieson P, O'Neill J, Durrant S, Henderson S, Green P, NewsomDavis J. Antibody-mediated pure neutrophil aplasia, recurrent myasthenia gravis and previous thymoma: case report and literature review. Q. J.Med., 1990; 74:57-61.

[4] Mamus S, Burton J, Groat J, Schulte D, Lobell M, Zanjani E. Ibuprofen-associated pure white-cell aplasia. N. Engl. J. Med., 1986; 314(10): 624-25. DOI: 10.1056/NEJM198603063141006

[5] Levitt L. Chlorpropamide-induced pure white cell aplasia. Blood. 1987; 69: 394-400.

[6] Visco C, Barcellini W, Maura F, Neri A, Cortelezzi A, Rodeghiero F. Autoimmune cytopenias in chronic lymphocytic leukemia. Am. J. Hematol., 2014; 89(11):1055-62.

DOI: $10.1002 /$ ajh. 23785

[7] Tesfa D, Keisu M, Palmblad J. Idiosyncratic drug-induced agranulocytosis: Possible mechanisms and management. Am. J. Hematol., 2009; 84(7):428-34. DOI: 10.1002/ajh.21433

[8] Tesfa D, Keisu M, Palmblad J. Idiosyncratic drug-induced agranulocytosis: Possible mechanisms and management. Am. J. Hematol., 2009; 84(7): 428-34. DOI: 10.1002/ajh.21433

[9] Uetrecht J. Reactive metabolites and agranulocytosis. Eur. J. Haematol., 1996; 57(60): 83-88. DOI: 10.1111/j.1600-0609.1996.tb01651.x

[10] Sultan S, Irfan S. Acquired idiopathic pure white cell aplasia: A rare cause of agranulocytosis. J. Appl. Haematol., 2014; 5(4):16163. DOI: $10.4103 / 1658-5127.146952$

[11] Casato M, Pucillo L, Leoni M, di Lullo L, Gabrielli A, Sansonno D, et al. Granulocytopenia after combined therapy with interferon and angiotensin-converting enzyme inhibitors: evidence for a synergistic hematologic toxicity. Am. J. Med., 1995; 99(4): 386-91. DOI: $10.1016 / \mathrm{s} 0002-9343(99) 80186-7$ 
[12] Rouveix B, Coulombel L, Aymard J, Chau F, Abel L. Amodiaquine-induced immune agranulocytosis. Br. J. Haematol., 1989; 71(1):7-11. DOI: 10.1111/j.1365-2141.1989.tb06266.x

[13] Soff G, Kadin M. Tocainide-induced reversible agranulocytosis and anemia. Arch. Intern. Med., 1987; 147(3):598-9. DOI: 10.1001/archinte.1987.00370030196040

[14] Adjei G, Goka B, Rodrigues O, Høegberg L, Alifrangis M, Kurtzhals J. Amodiaquine-associated adverse effects after inadvertent overdose and after a standard therapeutic dose. Ghana. Med. J., 2009; 43(3):135-38.

DOI: $10.4314 /$ gmj.v43i3.55340
[15] Lind D, Levi J, Vincent P. Amodiaquine-induced agranulocytosis: toxic effect of amodiaquine in bone marrow cultures in vitro. $\mathrm{Br}$. Med. J., 1973; 1(5851): 458-60. DOI: 10.1136/bmj.1.5851.458

[16] Clarke J, Neftel K, Kitteringham N, Park B. Detection of antidrug IgG antibodies in patients with adverse drug reactions to amodiaquine. Int. Arch. Allergy Immunol., 1991; 95(4): 369-75. DOI: $10.1159 / 000235475$

[17] Centers for Disease Control (CDC). Agranulocytosis associated with the use of amodiaquine for malaria prophylaxis. MMWR., Morbidity and mortality weekly report. 1986; 35(10): 165.

(C) 2017 National journal of health sciences.

This is an open-access article. 